Please do not remove this page

RMIT

UNIVERSITY

\title{
An empirical model for the equivalent translational compliance of steel studs
}

Davy, John; Guigou-Carter, Catherine; Villot, Michel

https://researchrepository.rmit.edu.au/esploro/outputs/9921858132601341/filesAndLinks?institution=61 RMIT_INST\&index=null

Davy, J., Guigou-Carter, C., \& Villot, M. (2012). An empirical model for the equivalent translational compliance of steel studs. Journal of the Acoustical Society of America, 131(6), 4615-4624.

https://doi.org/10.1121/1.4714354

Document Version: Accepted Manuscript

Published Version: https://doi.org/10.1121/1.4714354

Repository homepage: https://researchrepository.rmit.edu.au

(C) 2012 Acoustical Society of America

Downloaded On 2023/04/26 19:40:13 +1000

Please do not remove this page 
Davy, J, Guigou-Carter, C and Villot, M 2012, 'An empirical model for the equivalent translational compliance of steel studs', Journal of the Acoustical Society of America, vol. 131, no. 6, pp. 4515-4624.

An empirical model for the equivalent translational compliance of steel studs ${ }^{\mathrm{a}}$

John L. Davy ${ }^{\text {bc }}$

School of Applied Sciences, RMIT University, GPO Box 2476V Melbourne, Victoria 3001, Australia

Catherine Guigou-Carter

CSTB Département Acoustique et Éclairage, 24 Rue Joseph Fourier, 38400 Saint Martin

d’Hères, France

Michel Villot

CSTB Département Acoustique et Éclairage, 24 Rue Joseph Fourier, 38400 Saint Martin

d’Hères, France

Running title: The compliance of steel studs

a Portions of this work were presented in "The equivalent translational stiffness of steel studs," Proceedings of 20th International Congress on Acoustics, ICA 2010, Sydney, Australia, 23-27 August 2010.

${ }^{\mathrm{b}}$ Author to whom correspondence should be addressed. Electronic mail: john.davy@rmit.edu.au

${ }^{\text {c }}$ Current address: CSIRO Materials Science and Engineering, PO Box 56 Highett Victoria 3190, Australia. 
The effect of the resilience of the steel studs on the sound insulation of steel stud cavity walls can be modelled as an equivalent translational compliance in simple models for predicting the sound insulation of walls. Recent numerical calculations have shown that this equivalent translational compliance varies with frequency. This paper determines the values of the equivalent translational compliance of steel studs which make a simple sound insulation theory agree best with experimental sound insulation data for 126 steel stud cavity walls with gypsum plaster board on each side of the steel studs and sound absorbing material in the wall cavity. These values are approximately constant as a function of frequency up to $400 \mathrm{~Hz}$. Above $400 \mathrm{~Hz}$ they decrease approximately as a non-integer power of the frequency. The equivalent translational compliance also depends on the mass per unit surface area of the cladding on each side of the steel studs and on the width of the steel studs. Above $400 \mathrm{~Hz}$, this compliance also depends on the stud spacing. The best fit approximation is used with a simple sound insulation prediction model to predict the sound insulation of steel stud cavity walls whose sound insulation has been determined experimentally.

PACS numbers: 43.55.Rg, 43.55.Ti, 43.40.Rj, 43.20.Rz 


\section{INTRODUCTION}

Models for predicting the sound insulation of steel stud cavity walls need to know the compliance of the steel studs. This paper determines the values of the equivalent translational compliance of steel studs which make a simple sound insulation prediction model agree with a large database of sound insulation measurements. Regression curves are then best fitted to these values of equivalent translational compliance.

Heckl (Heckl, 1959a; b; Cremer et al., 2005) derived formulae for the sound power radiated on one side of an infinite plate excited by a point force and the sound power per unit length radiated from one side of an infinite plate excited by an infinite line source. These formulae only apply below the critical frequency of the plate. He used these results to predict the improvement in sound insulation obtained by attaching a lightweight panel at a distance from heavyweight wall with point or line connections to the heavy weight wall and filling the resulting wall cavity with sound absorbing material. Heckl's theory and those theories based on it ignore the mass of the connections and assume that the behaviour of each connection is independent of the other connections.

Sharp (1973; 1978) and Sharp et al. (1980) applied Heckl’s results to predict the sound insulation of lightweight cavity walls with rigid studs or rigid point connections. Gu and Wang (1983) modelled resilient steel studs as springs with an equivalent translational stiffness of 9 or 10 MPa. Davy (1990b; a) stated that Gu and Wang's formulae "are not obviously an extension of Sharp's formulae" and introduced an equivalent mechanical compliance (the inverse of equivalent mechanical stiffness) of $1 \times 10^{-6} \mathrm{~Pa}^{-1}$ into Fahy and Gardonio's (2006) version of Sharp's theory. Notice that Davy's value of equivalent mechanical compliance is a factor of 9 or 
10 more than Gu and Wang's compliance. Because Fahy had not integrated over angle of incidence, Davy performed the integration.

The results mentioned above only apply below the critical frequency. Davy (1991) extended his theory to above the critical frequency. Both Sharp’s and Davy’s theories included empirical correction factors below the critical frequency. Davy (1993) replaced his empirical correction factor with the effects of resonant vibration in both panels. He also found and corrected an error in his theory above the critical frequency. Unfortunately this paper introduced an apparent asymmetry into the theory. Davy was able to explain that the apparent asymmetry in panel critical frequency was due to total internal reflection. If this total internal reflection is taken into account, the apparent asymmetry in panel critical frequency is removed. Heckl (personal communication to first author in 1993) pointed out that there is still an asymmetry in panel total damping loss factors. However this asymmetry will only arise if the panels have identical critical frequencies and different total damping loss factors. The recommended approach in this case is to use the average total damping loss factor for both panels.

Vigran (2010b) gives a good summary of Sharp’s method of modelling sound transmission due to rigid studs and point connections. Vigran extends Sharp’s theory to above the critical frequency using a different approach to that of Davy.

Hongisto (2006) showed that Davy’s theory agreed well with measurements on steel stud walls with sound absorption in the cavity while $\mathrm{Gu}$ and Wang's theory did not. Unfortunately Davy's theory only agreed well, because as Hongisto also showed, Davy's theory for the sound transmission via a wall cavity with sound absorbing material produced results which were too high. It turned out that Davy's theoretical air borne results were approximately the same as the experimental steel stud structure borne results and thus produced excellent agreement. Davy 
(1998) modified his airborne theory by limiting the upper angle of integration to a maximum value of $61^{\circ}$. He also set the equivalent mechanical compliance of the steel studs to $0 \mathrm{~Pa}^{-1}$ and introduced "an empirical steel stud structure borne attenuation of $10 \mathrm{~dB}$ relative to wooden studs". In 2009, Davy (2009) recommended "a stud attenuation factor in the range from 0.02 to 0.2 ”. He actually used a stud attenuation factor of 0.04 to compare his theory with experimental results. Davy (2010) used an equivalent mechanical compliance of $1.6 \times 10^{-6} \mathrm{~Pa}^{-1}$ for steel studs but limited the predicted steel stud transmission to be greater than a minimum value of 0.005 .

Guigou-Carter et al. (1998) modelled the sound insulation of $10 \mathrm{~mm}$ plasterboard mounted by rigid or resilient line connections $50 \mathrm{~mm}$ from a heavyweight wall. The $50 \mathrm{~mm}$ cavity was filled with glass wool. Their resilient line connectors were assumed to have an equivalent translational stiffness of $10 \mathrm{MPa}$. Poblet-Puig et al. (2006) calculated the vibrational level difference between $9 \mathrm{~mm}$ and $13 \mathrm{~mm}$ gypsum plaster board wall leaves connected via steel studs and compared these differences with those calculated for line connections with a range of equivalent translational stiffnesses or a range of equivalent rotational stiffnesses. Guigou-Carter and Villot (2006) used this information to calculate the sound insulation at low frequencies of two gypsum plaster board steel stud cavity walls with sound absorbing material in the wall cavity. At higher frequencies they modelled the steel studs as resilient point connections situated at the positions of the screws used to attach the gypsum plaster board to the steel studs.

Research by Poblet-Puig (2008) and Poblet-Puig et al. (2009) has shown that a steel stud can be modelled as a translational spring with an equivalent translational stiffness which varies with frequency in the range from $10^{5}$ to $10^{8} \mathrm{~Pa}$. The constant value of equivalent mechanical compliance used in Davy (2010) corresponds to an equivalent translational stiffness of $6 \times 10^{5} \mathrm{~Pa}$ which lies towards the bottom end of the above range. The value of the minimum stud 
transmission used in Davy (2010) is $-23 \mathrm{~dB}$. This also lies in the 0 to $-40 \mathrm{~dB}$ stud transmission range determined by Poblet-Puig et al. (2009) for a standard steel stud. Vigran (2010a) has derived a best-fit third order polynomial approximation to the logarithm of Poblet-Puig's numerical values as a function of the logarithm of the frequency for the most common type of steel stud.

\section{USE OF POBLET-PUIG'S STIFFNESS VALUES}

Initially, the equivalent translational stiffness values of Poblet-Puig et al. (2009) for standard TC steel studs were used with Davy's (Davy, 2010) theory to predict the average of nine experimental measurements by the National Research Council of Canada (NRCC) (Halliwell et al., 1998). These nine measurements were made on walls consisting of two layers of $16 \mathrm{~mm}$ gypsum plasterboard on each side of $90 \mathrm{~mm}$ steel studs at $406 \mathrm{~mm}$ spacing. There was sound absorbing material in the wall cavity. This type of wall construction is denoted as $16+16-$ 90-406 in this paper. For walls where the thicknesses of gypsum plaster board on each side of the steel studs are different, the second leaf thicknesses are included in brackets. An example is $13+16(16+16)-90-406$. Some of the walls only had one layer rather than two layers of gypsum plasterboard on one side or both sides of the steel studs. An example is 13-90-406.

Walls with fire rated and non fire rated gypsum plaster board (with slightly different masses per unit area) were grouped together, as were walls with different sound absorbing material in the cavity. The NRCC report gives the actual mass per unit area of the gypsum plaster board. Because of the combination of different densities of gypsum plaster board into the same group, gypsum plaster board is assumed to have a density of $770 \mathrm{~kg} / \mathrm{m}^{2}$ in this paper and the nominal thickness of the gypsum plasterboard is used with this density to calculate the mass per unit area. The sound absorption coefficient of the cavity sound absorbing material is assumed to 
be 1. Note that Davy's (2009) theory limits the actual value of the sound absorbing material at low frequencies depending on the width of the cavity.

A single layer of gypsum plaster board is assumed to have a Young’s modulus of 2.2 GPa. Because two layers of gypsum plaster board on one side of the steel studs are only fastened at points by the screws, they can slide relative to each other when being bent by the sound. The result is that the critical frequency of two equal thicknesses of gypsum plaster board is almost the same as that of a single thickness. In the theoretical results of this paper this result is achieved by assuming that two thicknesses behave as a single thickness of the same total thickness with a Young's modulus of approximately one quarter of one of the original single layers. In this paper two layers of gypsum plaster board are assumed to have a Young's modulus of 0.6 GPa. The Poisson's ratio of gypsum plaster board is assumed to be 0.3 .

Based on the comparison between Davy's (2010) theory and the average of 5 NRCC measurements on walls with $16 \mathrm{~mm}$ of gypsum plaster board on each side of $40 \mathrm{~mm}$ double steel studs, the in-situ damping loss factor of gypsum plaster board is assumed to be 0.03 . There was a $10 \mathrm{~mm}$ gap between the $40 \mathrm{~mm}$ double steel studs giving a cavity width of $90 \mathrm{~mm}$. The cavity was filled with sound absorbing material. Since there are no direct connections through studs between the wall leaves, this wall type is denoted 16-90-none in this paper and the comparison is shown in Figure 1.

The in-situ damping loss factors have a significant effect on the theory for air borne sound transmission across the cavity above the critical frequency but only have a small effect below the critical frequency. However the theory for stud borne transmission across the cavity is affected by the in-situ damping loss factors across the whole frequency range. Thus it is not possible to distinguish between the effects of in-situ damping loss factors and the steel stud compliance from 
the steel stud sound insulation measurements. This is why the in-situ damping loss factor is determined from the no stud sound insulation measurements above the critical frequency and is assumed to be constant as a function of frequency. It should be noted that there is some evidence that the damping loss factor of materials may vary with frequency (Hongisto, 2001). It should also be noted that assuming different values of damping loss factor would produce different values of steel stud compliances. However the value chosen does work well for predicting the average of the five NRCC double stud measurements with a single layer of $16 \mathrm{~mm}$ gypsum plaster board on each side of the wall. It is possible that the use of double layers of gypsum plaster board on each side of the walls may introduce more damping and increase the damping loss factor.

The comparison between theory and the average of the nine experimental results for the 16+16-90-406 type is shown in Figure 2. It is apparent that the theoretical results are much more irregular than the experimental results. This is due to the irregularity of the numerically calculated equivalent translational stiffness. Nevertheless, the comparison was encouraging enough to proceed further.

\section{DERIVING COMPLIANCE FROM NRCC DATA}

One way forward would have been to fit a smooth curve to the numerically calculated values of equivalent translational stiffness as has been done by Vigran (2010a). Instead the decision was made to determine the values of the equivalent translational compliance which would make Davy’s (2010) theory agree with NRCC sound insulation measurements on steel stud walls (Halliwell et al., 1998). The 126 steel stud walls were grouped into 28 different classes of wall. These types of wall were labelled as described at the start of the previous section. For each wall type and third octave band centre frequency, the value of equivalent translational 
compliance which made zero or minimised the difference between theory and experiment was determined if possible. Davy's (2010) theory does not use the stud borne transmission theory below the mass-air-mass resonance frequency because in that frequency range the air cavity rigidly couples the two wall leaves. Thus an equivalent translational compliance could not be determined for frequencies below the mass-air-mass resonance frequency. In some situations, the theoretical air borne sound insulation was less than the experimental sound insulation. In these situations, it was also not possible to determine a meaningful value of equivalent stud compliance.

Figure 3 shows the equivalent translational compliance determined using this method for a 16+16-90-406 type of wall. Examination of Figure 3 suggests that the equivalent translational compliance is approximately constant up to about $400 \mathrm{~Hz}$. Above $400 \mathrm{~Hz}$, the relationship between the logarithm of the equivalent translational compliance and the logarithm of the frequency is approximately linear. In this frequency range, this linearity is very sensitive to the value of the critical frequency. The values of Young's modulus given above for both double and single layers of gypsum plaster board were determined by choosing the values which made the above relationship as linear as possible.

Also shown in Figure 3 are the equivalent translational compliances derived for the average of eleven 13-90-406 type NRCC measurements. These results show more variability than those derived from the 16+16-90-406 type walls because there is less difference between the theoretical studless sound insulation and the stud only sound insulation in this case. Since these are all greater than the compliances derived from the 16+16-90-406 type walls, it appears that the equivalent translational compliance depends on the properties of the gypsum plaster board leaves. 


\section{BEST FITTING TO COMPLIANCE VALUES}

Figure 4 shows the maximum and minimum values of equivalent translation compliance derived by making Davy's (2010) theory fit the 28 different wall type averages of the 126 NRCC (Halliwell et al., 1998) measurements on steel stud walls with sound absorbing material in their wall cavities. Because the equivalent translational compliance appears to decrease as a function of frequency above 400 or $500 \mathrm{~Hz}$, a linear regression in the frequency range from 400 to 6300 $\mathrm{Hz}$ was conducted of the natural logarithm of the compliance $C_{M}$ as a function of the natural logarithms of the frequency $f$, the reduced mass of the gypsum plasterboard wall leaves $m_{r}$, the steel stud spacing $b$ and the steel stud (cavity) width $d$.

The reduced mass $m_{r}$ is given by

$$
m_{r}=\frac{m_{1} m_{2}}{m_{1}+m_{2}}
$$

where $m_{i}$ is the mass per unit area of the ith wall leaf. It was chosen because it appears in the equation for the normal incidence mass-air-mass resonance angular frequency $\omega_{0}$,

$$
\omega_{0}=\sqrt{\frac{\rho_{0} c^{2}}{d m_{r}}} .
$$

In this equation $\rho_{0}$ is the ambient density of air, $c$ is the speed of sound in air and $d$ is the cavity (steel stud) width.

According to Davy (2010), the stud transmission ratio $J$ is given by

$$
J=\frac{2}{1+\left(1-\frac{4 \omega^{3 / 2} m_{1} m_{2} c C_{M}}{G}\right)^{2}}
$$

where

$$
G=m_{1} \omega_{c 2}^{1 / 2}+m_{2} \omega_{c 1}^{1 / 2}
$$


(Davy, 2009). The stud transmission ratio $J$ is the ratio of the vibrational energy transmitted from wall leaf 1 to wall leaf 2 by a resilient stud with an equivalent translation compliance of $C_{M}$ to that transmitted by a rigid stud $\left(C_{M}=0\right) . \omega_{c i}$ is the angular critical frequency of the ith wall leaf and $\omega$ is the angular frequency of the sound.

Inserting equation (4) into equation (3) gives

$$
J=\frac{2}{1+\left(1-\frac{4 \omega^{3 / 2} m_{1} m_{2} c C_{M}}{m_{1} \omega_{c 2}^{1 / 2}+m_{2} \omega_{c 1}^{1 / 2}}\right)^{2}} .
$$

If $\omega_{c 1}=\omega_{c 2}=\omega_{c}$, then equation (5) becomes

$$
J=\frac{2}{1+\left(1-\frac{4 \omega^{3 / 2} m_{r} c C_{M}}{\omega_{c}^{1 / 2}}\right)^{2}} .
$$

The appearance of the reduced mass $m_{r}$ in equation (6) is another reason for using it in the linear regression.

Using each side of the linear regression equation as the argument of the exponential function produces the following equation.

$$
C_{M}=A f^{x_{f}} m_{r}^{x_{m}} b^{x_{b}} d^{x_{d}} .
$$

The linear regression produced the values and $95 \%$ confidence limits shown in Table I for the constants in equation (7). Notice that at the $95 \%$ confidence level, $A$ is statistically different from 1 and all four $x$ 's are statistically different from 0 .

Because the equivalent translational compliance appears to be approximately constant as a function of frequency below 400 or $500 \mathrm{~Hz}$, a linear regression in the frequency range from 63 to $500 \mathrm{~Hz}$ was conducted of the natural logarithm of the compliance $C_{M}$ as a function of the natural logarithms of the same variables used in the previous linear regression. This linear regression 
produced the values and 95\% confidence limits shown in Table II for the constants in equation (7).

At the $95 \%$ confidence level, $A$ is statistically different from $1, x_{m}$ and $x_{d}$ are statistically different from 0 and $x_{f}$ and $x_{b}$ are not statistically different from 0 . The fact that $x_{f}$ is not statistically different from zero confirms the visual observation that the equivalent translational compliance is not a function of frequency in the frequency range from 63 to $500 \mathrm{~Hz}$.

Because $x_{f}$ and $x_{b}$ are not statistically different from 0 , a new linear regression in the frequency range from 63 to $500 \mathrm{~Hz}$ was conducted of the natural logarithm of the compliance $C_{M}$ as a function of the natural logarithms of the reduced mass of the gypsum plasterboard wall leaves $m_{r}$ and the steel stud (cavity width) $d$. Using each side of this linear regression equation as the argument of the exponential function produces the following equation.

$$
C_{M}=A m_{r}^{x_{m}} d^{x_{d}} .
$$

The linear regression produced the values and 95\% confidence limits shown in Table III for the constants in equation (8).

Looking at Figure 4, the values of equivalent translational compliance are much more tightly grouped in the frequency range from 2500 to $6300 \mathrm{~Hz}$. Thus it is of interest to repeat the original linear regression restricted to this frequency range. The results are shown in Table IV.

Given that the confidence intervals for $x_{f}$ and $x_{m}$ in Table I are less than -1.5 and -1 respectively, while they are greater than -1.5 and -1 respectively in Table IV, it is interesting to speculate that the true values of $x_{f}$ and $x_{m}$ in the high frequency range are -1.5 and -1 respectively. Also $x_{b}$ in Table IV is not statistically significantly different from -0.5 at the $95 \%$ confidence level and it is also interesting to speculate that the true value of $x_{b}$ in the high 
frequency range is -0.5 . These speculations lead to an interesting conclusion. They imply that for a constant value $d$, the equivalent translational compliance is given by

$$
C_{M}=B b^{-1 / 2} \omega^{-3 / 2} m_{r}^{-1}
$$

in the high frequency range where $B$ is a constant. Substituting equation (9) into equation (6) gives

$$
J=\frac{2}{1+\left(1-\frac{4 B c}{b^{1 / 2} \omega_{c}^{1 / 2}}\right)^{2}} .
$$

This implies that for constant angular critical frequency $\omega_{c}$ constant stud spacing $b$ and constant speed of sound $c$, the stud transmission ratio $J$ is constant. This speculative result agrees with the assumption of a constant or a minimum stud transmission ratio made by Davy (1998; 2009; 2010).

If the magnitude of the second term in the brackets of equation (10) is much greater than one, equation (10) becomes

$$
J=\frac{b \omega_{c}}{8 B^{2} c^{2}} .
$$

Equation (29) of Davy (2010) gives the stud borne transmission coefficient $\tau$ as

$$
\tau=\frac{32 \rho_{0}^{2} c^{3} H J}{G^{2} b \omega^{2}}
$$

where $H$ is the $D$ of equation (50) of Davy (2009).

Substituting equation (11) into equation (12) gives

$$
\tau=\frac{4 \rho_{0}^{2} c \omega_{c} H}{G^{2} B^{2} \omega^{2}} .
$$

Thus the speculative assumptions suggest that the stud borne sound insulation of a steel stud gypsum plaster board cavity wall with sound absorbing material in the wall cavity is independent of the stud spacing at medium and high frequencies. This is not the case at low frequencies where Table II shows that the equivalent translational compliance is independent of the stud 
spacing and thus that equation (12) retains its inverse dependence on the stud spacing $b$. These results are in rough agreement with Hongisto et al. (2002). This reference says the following about steel stud spacing. “The influence of stud spacing above $200 \mathrm{~Hz}$ was roughly the same as with rigid studs, viz. only a couple of decibels. The overall effect of stud spacing was practically negligible with flexible studs compared to rigid studs.”

Another conclusion to be drawn from an examination of Tables I to IV is that the equivalent translational compliance depends more strongly on the stud (cavity) width at low frequencies than at medium and high frequencies.

Some caution should be exercised with regard to the dependence on stud spacing and stud (cavity) width. Only two stud spacings (406 and $610 \mathrm{~mm}$ ) were considered. All but two of the walls whose results were analysed had 65 or $90 \mathrm{~mm}$ stud widths. The other two had $150 \mathrm{~mm}$ stud widths. On the other hand the values analysed are the most common used in practice.

In this paper the equivalent translational compliance $C_{M}$ will be calculated as the minimum of equation (7) calculated using the constant values in Table I and equation (8) using the constant values in Table III. The equivalent translational stiffness is calculated by inverting of the value of the equivalent translational compliance.

Defining

$$
x=\log _{10}(f),
$$

then Vigran's (2010a) best fit third order polynomial approximation, to Poblet-Puig et al.'s (2009) numerically calculated equivalent translational stiffness data for TC steel studs, is given by the following equation.

$$
-\log _{10}\left(C_{M}\right)=0.6286 x^{3}-4.4051 x^{2}+10.3323 x-7.0722 \text {. }
$$

Figure 5 compares the best fit equations of this paper (Davy et al.) and that of Vigran with the Poblet-Puig et al. data for $70 \mathrm{~mm}$ wide TC steel studs spaced at $600 \mathrm{~mm}$ with $13 \mathrm{~mm}$ gypsum 
plasterboard on each side. The equivalent translation compliance of $1.6 \times 10^{-6} \mathrm{~Pa}^{-1}$ recommended by Davy (2010) is in rough agreement with the low frequency value of this paper of $1.9 \times 10^{-6}$ $\mathrm{Pa}^{-1}$ shown in Figure 5.

\section{USE OF THE BEST FIT EQUATIONS}

Figure 6 shows the comparison of the stud transmission ratio $J(\mathrm{~dB})$ calculated using equation (3) and the best fit equations for the equivalent translational compliance of this paper (Davy et al.), the best fit equation of Vigran (2010a) and Poblet-Puig et al.'s (2009) numerical values for $70 \mathrm{~mm}$ wide TC steel studs spaced at $600 \mathrm{~mm}$ with $13 \mathrm{~mm}$ gypsum plasterboard on each side. The minimum value of the stud transmission ratio of $-23 \mathrm{~dB}$ recommended by Davy (2010) is in rough agreement with the high frequency results of this paper shown in Figure 6.

Table V shows the mean, standard deviation, maximum and minimum of sound insulation theory (Davy, 2010) minus experiment (Halliwell et al., 1998) for the third octave frequency bands from 50 to $6300 \mathrm{~Hz}$ for the 28 different wall types using the best fit equations derived in this paper for equivalent translational compliance. The overall row in Table V shows the average value of the mean differences, the root mean square of the standard deviations of the differences, the maximum of the maximum differences and the minimum of the minimum differences. For comparison, the last row of Table $\mathrm{V}$ shows the values for the 16-90-none wall type whose theoretical and experimental results are graphed in Figure 1. This last wall type is without studs which bridge the wall cavity. The overall standard deviation of $2.4 \mathrm{~dB}$ is not excessively greater than the $1.9 \mathrm{~dB}$ standard deviation of the 16-90-none wall type without bridging studs.

Figure 7 shows the comparison of the average of nine NRCC experimental results (Halliwell et al., 1998) with theoretical calculations for a 16+16-90-406 type wall using the equivalent translational compliance best fit equations for steel studs in Davy's (2010) theory. 
This figure should be compared with Figure 2. From Table V, it can be seen that the mean, standard deviation, maximum and minimum of the theory minus experiment for Figure 7 are 0.8, 1.8, 3.1 and $-4.5 \mathrm{~dB}$ respectively. The equivalent numbers for Figure 2 are 3.0, 5.7, 11.2 and -8.4 dB. Thus it can be seen from both these sets of numbers and the figures that the best fit equations derived in this paper perform better overall than the numerical calculations of PobletPuig et al. (2009). This is thought to be due to the very complicated vibrational situation that the numerical calculations of Poblet-Puig et al. (2009) are attempting to analyse from first principles. Nevertheless, the calculations of Poblet-Puig et al. (2009) are very important because they provide a first principles theoretical explanation of why steel studs behave vibrationally in the way that they do.

The use of the compliance equations derived in this paper with a different sound insulation prediction method was tested by using the CSTB prediction method for line connections with the compliance equations to predict the sound insulation values of the 28 classes of steel stud wall into which this paper has divided the NRCC data. It should be noted that CSTB prediction method uses an equivalent fluid method to model the absorbing material in the cavity, and spatial filtering technique for taking into account the double wall dimensions; the diffuse incident acoustic field being defined by incidence angle varying from $0^{\circ}$ to $90^{\circ}$. Therefore, differences between CSTB and Davy's prediction can be expected around the double wall cavity resonance frequency, as well as around the critical frequency. The mean differences between the theoretical predictions and the experimental results for both the Davy's prediction method and the CSTB prediction method are shown in Figure 8. The two mean difference curves cross each other at 125 and $2000 \mathrm{~Hz}$. In the frequency range from 50 to $100 \mathrm{~Hz}$, the mean differences for Davy’s 
and the CSTB methods are 1.6 and $-1.6 \mathrm{~dB}$ respectively. The mean differences are -0.9 and 2.3 $\mathrm{dB}$ in the 160 to $1600 \mathrm{~Hz}$ range and 0.3 and $-6.9 \mathrm{~dB}$ in the 2500 to $6300 \mathrm{~Hz}$ range.

The standard deviations of the differences are shown in Figure 9. It is surprising how close the two curves are, except in the neighbourhood of the two mean difference curve crossing frequencies at 125 and $2000 \mathrm{~Hz}$. This suggests that the theories underlying both prediction methods are fairly similar. The differences cannot tell us which prediction method is better, but only whether the prediction methods can use the same values of compliance. It is quite possible than the equivalent translation compliance could change dramatically in value at the critical frequency. However, it is clear that the CSTB prediction method would need an empirical correction factor above the critical frequency if used with the values of compliance derived in this paper. Below the critical frequency, the values of the differences are probably acceptable for both correction methods and no empirical correction factor is need.

There is great variability in the experimental measurements of the sound insulation of double steel stud gypsum plaster board cavity walls between different laboratories (Fausti et al., 1999). This is at least partially due to the transmission of structure borne sound from the excited wall leaf to the other wall leaf via the frame in which the wall is constructed (Smith et al., 1999). Wood frames produce more coupling than steel frames and concrete frames give less coupling than either steel or wood.

The same appears to be true with single steel stud cavity walls. An exposed area of the mounting frame can also act as part of a flanking transmission path (Warnock, 1982). Figure 10 shows the maximum and minimum values of the sound reduction index at each third octave band frequency across 13 measurements on a 16-90-610 commissioned by United States Gypsum in a number different laboratories. The experimental data was provided to the first author in 
spreadsheet format by Warnock (personal communication). Also shown on Figure 10 are the Davy and CSTB predictions using the compliance formulae developed in this paper. From 200 to $2000 \mathrm{~Hz}$, both predictions are reasonably close to the maximum of the measured values. At and above $2500 \mathrm{~Hz}$, the Davy prediction is close to the maximum of the measured values while the CSTB prediction is fairly close to the minimum of the measured values. From 80 to $125 \mathrm{~Hz}$, both predictions are close to the minimum values. Given that the larger experimental values of the sound reduction index would be expected to be more correct because they are likely to have been less affected by coupling between the wall leaves at the edges of the wall, the agreement between the predicted values and the experimental values is not too bad considering the large range of the experimental values.

\section{STUDS WITH DIFFERENT CROSS SECTIONS}

The NRCC data (Halliwell et al., 1998) only includes measurements on walls with standard TC cross section steel studs. In order to see the effect of different steel stud cross sections the equivalent translational compliances calculated by Poblet-Puig et al. (2009) for O, S, LR and AWS cross sectional studs were divided by the equivalent translational compliances calculated by Poblet-Puig et al. (2009) for TC cross sectional studs. The results are shown in Figure 11. The average compliance ratio for $\mathrm{O}$ and $\mathrm{S}$ cross sectional steel studs is close to one. The average compliance ratio for LR and AWS cross sectional steel studs is greater than one. Because the ratio is the important quantity, the averages, standard deviations and 95\% confidence limits of the natural logarithms of the compliance ratios were calculated for the four different cross sectional studs. The exponential of the average of the natural logarithms of the compliance ratios was then taken to obtain an "average" of the compliance ratio. This is equivalent to taking a geometric average. The results are shown in Table VI. 
The averages of the natural logarithms of the compliance ratios for $\mathrm{O}$ and $\mathrm{S}$ cross sectional steel studs are not statistically significantly different from 0 at the $95 \%$ confidence level while these averages for LR and AWS cross sectional steel studs are statistically significantly different from zero at the $95 \%$ confidence level. This means that the geometric averages of the compliance ratios for $\mathrm{O}$ and $\mathrm{S}$ cross sectional steel studs are not statistically significantly different from one while the geometric averages of the compliance ratios for LR and AWS cross sectional steel studs are statistically significantly different from one. To calculate the equivalent translational compliance for O, S, LR and AWS cross sectional studs, it is recommended that the equivalent translational compliance for TC cross sectional studs be multiplied by the appropriate factor from the bottom line of Table VI. Since the geometric averages of the compliance ratios for O and S cross sectional studs are not statistically significantly different from one, it would also be permissible to set the compliance ratios for these stud cross sections to one.

A compliance ratio larger than one implies that the corresponding studs will have less effect on the double wall behaviour in the mid to high frequency range than the standard reference studs. This means that the sound reduction index will be improved in this frequency range.

\section{CONCLUSIONS}

This paper has derived empirical best fit formulae for the equivalent translational compliance of standard steel studs by making Davy's (2010) sound insulation theory agree with the experimental measurements of the National Research Council of Canada (NRCC) on 126 different gypsum plaster board steel stud walls with sound absorbing material in their wall cavities. The values of the equivalent translational stiffness of standard steel studs are easily obtained by inverting the calculated values of equivalent translational compliance. 
The equivalent translational compliance or stiffness depends on the masses per unit area of gypsum plaster board fastened to each side of the steel studs and the width of the steel studs (which is also the cavity width). Above 400 or $500 \mathrm{~Hz}$, it also depends on the frequency and the spacing between the steel studs.

The values of equivalent translational compliance derived in this paper and the stud velocity transmission ratios derived from them are in rough agreement with values proposed previously by Davy.

When used with Davy's (2010) sound insulation theory, the empirical best fit formulae for equivalent translational stud compliance are reasonably successful at predicting the NRCC experimental sound insulation results from which the empirical best fit formulae were derived. The use of the empirical best fit equations derived in this paper with the CSTB prediction method gave acceptable agreement with the NRCC data below the critical frequency, but under estimated the sound insulation above the critical frequency. Thus the CSTB method would need an empirical correction factor above the critical frequency if used with the equivalent translation compliances derived in this paper. Other theories of sound insulation with which the empirical best fit equations of this paper could possibly be used include those of Craik and Smith (2000b; a), Wang et al. (2005), Poblet-Puig (2008), Legault and Atalla (2009; 2010) and Vigran (2010a; b).

\section{REFERENCES}

Craik, R. J. M., and Smith, R. S. (2000a). "Sound transmission through double leaf lightweight partitions part I: airborne sound," Appl. Acoust. 61, 223-245.

Craik, R. J. M., and Smith, R. S. (2000b). "Sound transmission through lightweight parallel plates. Part II: structure-borne sound," Appl. Acoust. 61, 247-269. 
Cremer, L., Heckl, M., and Petersson, B. A. T. (2005). "Section 7.6.4 Radiation from externally excited bending waves," in Structure-borne sound - Structural vibrations and sound radiation at audio frequencies (Springer-Verlag, Berlin), pp. 492-497.

Davy, J. L. (1990a). "A model for predicting the sound transmission loss of walls," in The Australian Vibration and Noise Conference 1990 (Institution of Engineers, Australia, Melbourne, Australia), pp. 23-27.

Davy, J. L. (1990b). "Predicting the sound transmission loss of cavity walls," in Interior noise climates: National Conference of the Australian Acoustical Society (Australian Acoustical Society, Perth, Australia), pp. 1-16.

Davy, J. L. (1991). "Predicting the sound insulation of stud walls," in Costs of Noise: Proceedings of Inter-Noise 91 : International Conference on Noise Control Engineering, edited by A. Lawrence (Australian Acoustical Society, Sydney, Australia), pp. 251-254.

Davy, J. L. (1993). "The sound transmission of cavity walls due to studs," in Proceedings of Inter-Noise 93: International Conference on Noise Control Engineering, edited by P. Chapelle, and G. Vermeir (Belgium Acoustical Association, Leuven, Belgium), pp. 975-978.

Davy, J. L. (1998). "Problems in the theoretical prediction of sound insulation," in Sound and Silence: Setting the Balance. Proceedings of Internoise 98 : International Conference on Noise Control Engineering, edited by V. C. Goodwin, and D. C. Stevenson (New Zealand Acoustical Society Inc., Christchurch, New Zealand), pp. 162-165.

Davy, J. L. (2009). "Predicting the sound insulation of walls," Build. Acoust. 16, 1-20.

Davy, J. L. (2010). "The improvement of a simple theoretical model for the prediction of the sound insulation of double leaf walls," J. Acoust. Soc. Am. 127, 841-849. 
Fahy, F., and Gardonio, P. (2006). "Section 5.10 Mechanical stiffening and coupling of double partition leaves," in Sound and structural vibration - Radiation, transmission and response (Academic Press, London, United Kingdom), pp. 323-330.

Fausti, P., Pompoli, R., and Smith, R. S. (1999). "An intercomparison of laboratory measurements of airborne sound insulation of lightweight plasterboard walls," Build. Acoust. 6, $127-140$.

Gu, Q., and Wang, J. (1983). "Effect of Resilient Connection on Sound Transmission Loss of Metal Stud Double Panel Partitions," Chinese J. Acout. 2, 113-126.

Guigou-Carter, C., and Villot, M. (2006). "Analytical and experimental study of single frame double wall," in Euronoise 2006 (The Acoustical Society of Finland and VTT, Tampere, Finland), pp. 1-6.

Guigou-Carter, C., Villot, M., and Vernois, L. (1998). "Study of cavity ties for improving efficiency of acoustical lining," in Euronoise 1998 (Munich, Germany), pp. 1-6.

Halliwell, R. E., Nightingale, T. R. T., Warnock, A. C. C., and Birta, J. A. (1998). "Gypsum board walls: transmission loss data," in Internal Report IRC-IR-761 (Institute for Research in Construction, National Research Council of Canada, Ottawa, Canada), pp. 1-368.

Heckl, M. (1959a). "Schallabstralung von Platten bei Punktförmiger Anregung (Sound radiation from plates with point excitation)," Acust. 9, 371-380.

Heckl, M. (1959b). "Untersuchungen über die Luftschalldämmung von Doppelwänden mit Schallbrücken (Investigations on the airborne sound insulation of double walls with sound bridges)," in The Third International Congress on Acoustics, edited by L. Cremer (Elsevier Publishing Company, Stuttgart, Germany), pp. 1010-1014. 
Hongisto, V. (2001). "Case study of flanking transmission through double structures," Appl. Acoust. 62, 589-599.

Hongisto, V. (2006). "Sound Insulation of Double Panels - Comparison of Existing Prediction Models," Acta Acust. Acust. 92, 61-78.

Hongisto, V., Lindgren, M., and Helenius, R. (2002). "Sound insulation of double walls - an experimental parametric study," Acta Acust. Acust. 88, 904-923.

Legault, J., and Atalla, N. (2009). "Numerical and experimental investigation of the effect of structural links on the sound transmission of a lightweight double panel structure," J. Sound Vib. 324, 712-732.

Legault, J., and Atalla, N. (2010). "Sound transmission through a double panel structure periodically coupled with vibration insulators," J. Sound Vib. 329, 3082-3100.

Poblet-Puig, J. (2008). "Numerical modelling of sound transmission in lightweight structures," (Universitat Politècnica de Catalunya (UPC)), pp. 1-244.

Poblet-Puig, J., Rodriguez-Ferran, A., Guigou-Carter, C., and Villot, M. (2006). "Experimental and numerical characterization of metallic studs," in Euronoise 2006 (The Acoustical Society of Finland and VTT, Tampere, Finland), pp. 1-6.

Poblet-Puig, J., Rodriguez-Ferran, A., Guigou-Carter, C., and Villot, M. (2009). "The role of studs in the sound transmission of double walls," Acta Acust. Acust. 95, 555-567.

Sharp, B. H. (1973). "A study of techniques to increase the sound insulation of building elements," in Wyle Laboratories Report WR 73-5, Wyle Laboratories Research Staff, El Segundo, California, distributed as PB-222 829, National Technical Information Service, United States Department of Commerce, Springfield, Virginia., pp. 1-227. 
Sharp, B. H. (1978). "Prediction Methods for the Sound Transmission of Building Elements," Noise Control Eng. J. 11, 53-63.

Sharp, B. H., Kasper, P. K., and Montroll, M. L. (1980). "Sound Transmission through Building Structures - Review and Recommendations for Research," in NBS-GCR-80-250, National Bureau of Standards, United States Department of Commerce, Washington, D. C., . Distributed as PB81-187072, National Technical Information Service, United States Department of Commerce, Springfield, Virginia, pp. 1-147.

Smith, R. S., Pompoli, R., and Fausti, P. (1999). "An investigation into the reproducibility values of the European inter-laboratory test for lightweight walls," Build. Acoust. 6, 187-210.

Vigran, T. E. (2010a). "Sound insulation of double-leaf walls - allowing for studs of finite stiffness in the transfer matrix scheme," Appl. Acoust. 71, 616-621.

Vigran, T. E. (2010b). "Sound transmission in multilayered structires - Introducing finite structural connections in the transfer matrix method," Appl. Acoust. 71, 39-44.

Wang, J., Lu, T. J., Woodhouse, J., Langley, R. S., and Evans, J. (2005). "Sound transmission through lightweight double-leaf partitions: theoretical modelling," J. Sound Vib. 286, 817-847.

Warnock, A. C. C. (1982). "Influence of specimen frame on sound-transmission loss measurement," Appl. Acoust. 15, 307-314. 
Table I. Values and confidence limits for the constants in equation (7) in the frequency range from 400 to $6300 \mathrm{~Hz}$.

\begin{tabular}{|l|l|l|l|}
\hline Constant & Value & $95 \%$ Upper Limit & $95 \%$ Lower Limit \\
\hline$A$ & 1.74 & 2.94 & 1.03 \\
\hline$x_{f}$ & -1.81 & -1.77 & -1.84 \\
\hline$x_{m}$ & -1.40 & -1.29 & -1.51 \\
\hline$x_{b}$ & -0.75 & -0.59 & -0.92 \\
\hline$x_{d}$ & 0.28 & 0.43 & 0.13 \\
\hline
\end{tabular}


Table II. Values and confidence limits for the constants in equation (7) in the frequency range from 63 to $500 \mathrm{~Hz}$.

\begin{tabular}{|l|l|l|l|}
\hline Constant & Value & $95 \%$ Upper Limit & $95 \%$ Lower Limit \\
\hline$A$ & $8.5 \times 10^{-5}$ & $3.1 \times 10^{-4}$ & $2.3 \times 10^{-5}$ \\
\hline$x_{f}$ & 0.0134 & 0.133 & -0.106 \\
\hline$x_{m}$ & -1.09 & -0.82 & -1.35 \\
\hline$x_{b}$ & -0.02 & 0.35 & -0.40 \\
\hline$x_{d}$ & 0.81 & 1.19 & 0.42 \\
\hline
\end{tabular}


Table III. Values and confidence limits for the constants in equation (8) in the frequency range from 63 to $500 \mathrm{~Hz}$.

\begin{tabular}{|l|l|l|l|}
\hline Constant & Value & $95 \%$ Upper Limit & $95 \%$ Lower Limit \\
\hline$A$ & $9.3 \times 10^{-5}$ & $2.7 \times 10^{-4}$ & $3.2 \times 10^{-5}$ \\
\hline$x_{m}$ & -1.09 & -0.83 & -1.35 \\
\hline$x_{d}$ & 0.80 & 1.19 & 0.41 \\
\hline
\end{tabular}


Table IV. Values and confidence limits for the constants in equation (7) in the frequency range from 2500 to $6300 \mathrm{~Hz}$.

\begin{tabular}{|l|l|l|l|}
\hline Constant & Value & $95 \%$ Upper Limit & $95 \%$ Lower Limit \\
\hline$A$ & 0.0120 & 0.0196 & 0.0073 \\
\hline$x_{f}$ & -1.37 & -1.32 & -1.43 \\
\hline$x_{m}$ & -0.77 & -0.71 & -0.83 \\
\hline$x_{b}$ & -0.58 & -0.49 & -0.66 \\
\hline$x_{d}$ & 0.22 & 0.30 & 0.15 \\
\hline
\end{tabular}


Table V. The mean, standard deviation, maximum and minimum of sound insulation theory (Davy, 2010) minus experiment (Halliwell et al., 1998) for the third octave frequency bands from 50 to $6300 \mathrm{~Hz}$ for different wall types.

\begin{tabular}{|l|l|l|l|l|}
\hline Wall Type & mean $(\mathrm{dB})$ & std dev $(\mathrm{dB})$ & $\max (\mathrm{dB})$ & $\min (\mathrm{dB})$ \\
\hline $13-65-406$ & -0.2 & 3.2 & 6.9 & -4.0 \\
\hline $13-65-610$ & 0.8 & 2.5 & 5.7 & -2.5 \\
\hline $13-90-406$ & 0.0 & 2.7 & 5.0 & -4.0 \\
\hline $13-90-610$ & -0.2 & 2.4 & 5.7 & -4.6 \\
\hline $13-150-610$ & -2.6 & 3.6 & 4.7 & -6.1 \\
\hline $16-65-406$ & 0.6 & 2.7 & 6.9 & -4.2 \\
\hline $16-65-610$ & 0.8 & 2.6 & 7.0 & -3.9 \\
\hline $16-90-406$ & 0.3 & 2.2 & 4.7 & -2.9 \\
\hline $16-90-610$ & 0.0 & 2.5 & 6.0 & -3.2 \\
\hline $16-150-610$ & -0.5 & 2.4 & 3.1 & -5.9 \\
\hline $13(13+13)-65-406$ & 0.8 & 2.5 & 6.0 & -3.8 \\
\hline $13(13+13)-65-610$ & -0.2 & 2.3 & 6.5 & -3.5 \\
\hline $13(13+13)-90-406$ & 0.8 & 1.9 & 5.1 & -1.7 \\
\hline $13(13+13)-90-610$ & 0.1 & 2.4 & 5.7 & -4.1 \\
\hline $16(16+13)-65-610$ & -0.2 & 2.4 & 6.2 & -3.8 \\
\hline $16(16+16)-65-406$ & 0.1 & 2.6 & 5.3 & -5.4 \\
\hline $16(16+16)-65-610$ & 0.5 & 2.3 & 6.0 & -3.2 \\
\hline $16(16+16)-90-406$ & 0.4 & 1.6 & 3.7 & -2.0 \\
\hline $16(16+16)-90-610$ & 0.4 & 1.7 & 3.6 & -2.2 \\
\hline $13+13-65-406$ & -0.2 & 2.3 & 5.1 & -4.0 \\
\hline $13+13-65-610$ & -0.3 & 2.6 & 5.0 & -4.8 \\
\hline $13+13-90-406$ & 0.1 & 1.4 & 3.8 & -2.9 \\
\hline $13+13-90-610$ & 0.1 & 2.8 & 5.9 & -4.4 \\
\hline $13+16(16+16)-90-406$ & -0.2 & 2.1 & 4.0 & -3.9 \\
\hline $16+16-65-406$ & -1.3 & 2.5 & 4.3 & -6.4 \\
\hline $16+16-65-610$ & -0.6 & 2.0 & 3.9 & -4.1 \\
\hline $16+16-90-406$ & -0.8 & 1.8 & 3.1 & -4.5 \\
\hline $16+16-90-610$ & -0.5 & 2.4 & 3.4 & -4.6 \\
\hline Overall & -0.1 & 2.4 & 7.0 & -6.4 \\
\hline & & & & \\
\hline & & & & \\
\hline
\end{tabular}


Table VI. The averages, standard deviations and 95\% confidence limits of the natural logarithms of the compliance ratios for the four different cross sectional studs. The last line shows the exponential of the average of the natural logarithms of the compliance ratios. This is equivalent to taking a geometric average.

\begin{tabular}{|l|l|l|l|l|}
\hline Cross Section & O & S & LR & AWS \\
\hline Average of Ln & -0.31 & -0.02 & 0.68 & 1.22 \\
\hline Std. Dev. Of Ln & 1.90 & 1.21 & 1.71 & 2.11 \\
\hline $\pm 95 \%$ CL of Ln & 0.74 & 0.47 & 0.66 & 0.84 \\
\hline Geometric Mean & 0.73 & 0.98 & 1.96 & 3.39 \\
\hline
\end{tabular}




\section{FIGURE CAPTIONS}

Figure 1. Comparison of the average of five NRCC experimental results with theoretical calculations for a 16-90-none type wall using Davy's (2010) theory.

Figure 2. Comparison of the average of nine NRCC experimental results (Halliwell et al., 1998) with theoretical calculations for a 16+16-90-406 type wall using Poblet-Puig et al.'s (2009) equivalent translational stiffness values for TC steel studs in Davy's (2010) theory.

Figure 3. The equivalent translational compliance required to make Davy's (2010) theory agree with the average of nine 16+16-90-406 type and eleven 13-90-406 type NRCC experimental results (Halliwell et al., 1998).

Figure 4. The maximum and minimum values of equivalent translational compliance of steel studs derived by making Davy’s (2010) theory fit NRCC experimental data (Halliwell et al., 1998).

Figure 5. Comparison of the best fit equations of this paper (Davy et al.) and that of Vigran (2010a) for the equivalent translational compliance with the Poblet-Puig et al.'s (2009) data for $70 \mathrm{~mm}$ wide TC steel studs spaced at $600 \mathrm{~mm}$ with $13 \mathrm{~mm}$ gypsum plasterboard on each side.

Figure 6. Comparison of stud transmission ratio $(\mathrm{dB})$ calculated using equation (3) and the best fit equations for the equivalent translational compliance of this paper (Davy et al.), the best fit equation of Vigran (2010a) and Poblet-Puig et al.'s (2009) numerical data for 70 mm wide TC steel studs spaced at $600 \mathrm{~mm}$ with $13 \mathrm{~mm}$ gypsum plasterboard on each side.

Figure 7. Comparison of the average of nine NRCC experimental results (Halliwell et al., 1998) with theoretical calculations for a 16+16-90-406 type wall using the equivalent translational compliance best fit equations for steel studs in Davy's (2010) theory.

Figure 8. The mean differences between the theoretical predictions and the experimental results for Davy's prediction method and the CSTB prediction method.

Figure 9. The standard deviations of differences between the theoretical predictions and the experimental results for Davy's prediction method and the CSTB prediction method. 
Figure 10. The maximum and minimum experimental values from 13 United States Gypsum sound insulation measurements on a 16-90-610 wall compared with the Davy and CSTB prediction methods.

Figure 11. The ratio of the equivalent translational compliance of O, S, LR, AWS cross sectional steel studs to that of TC cross sectional steel studs as calculated by Poblet-Puig et al. (2009). 


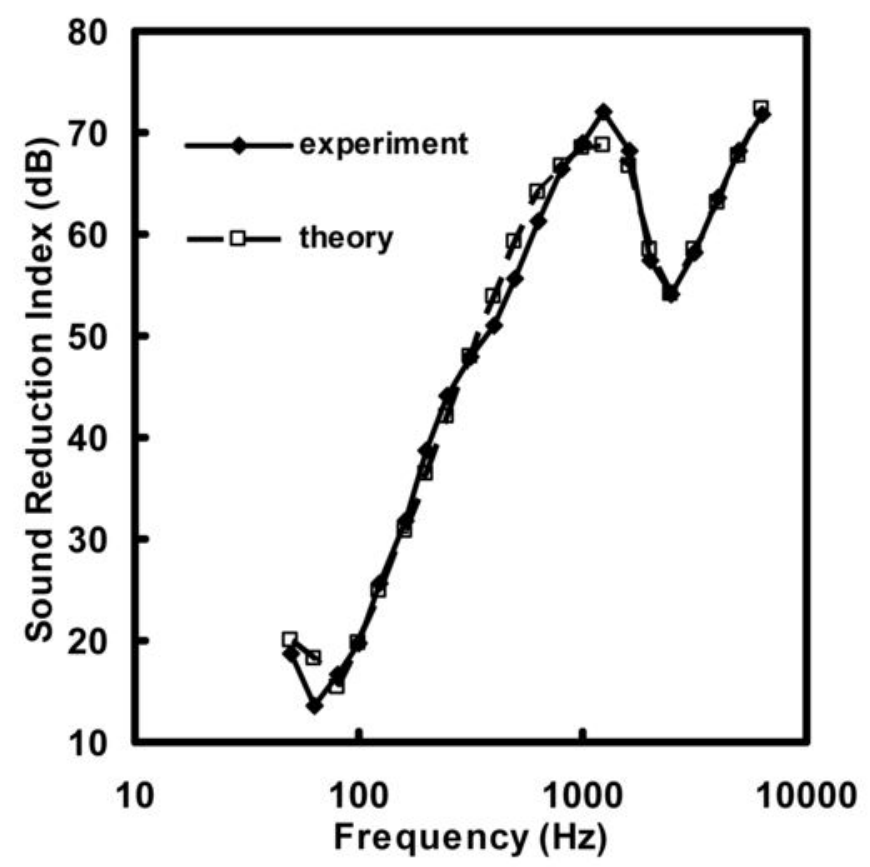




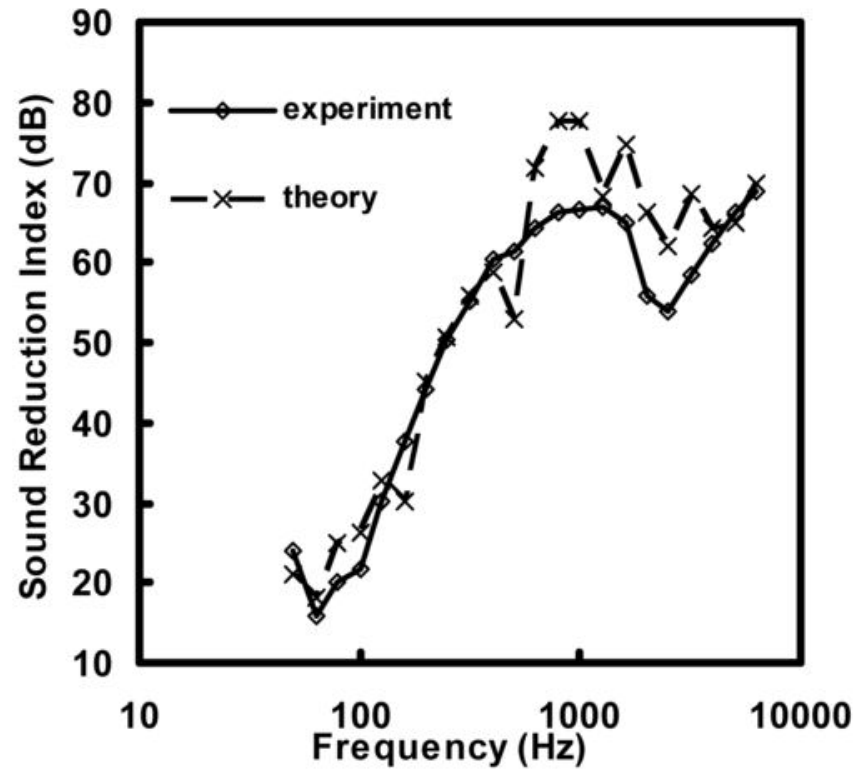




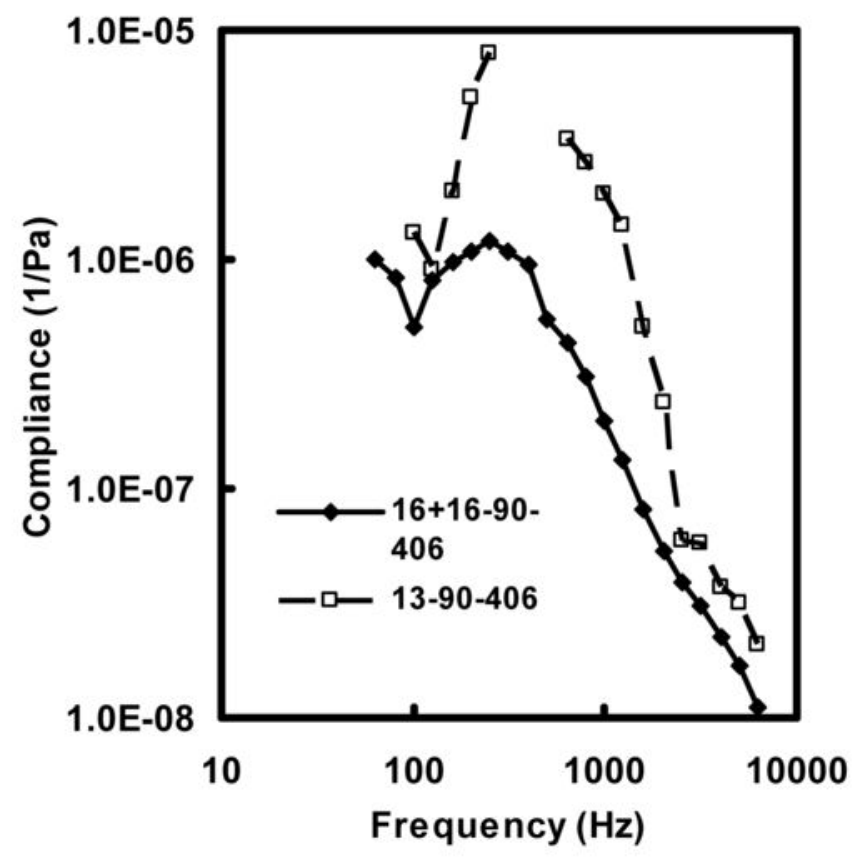




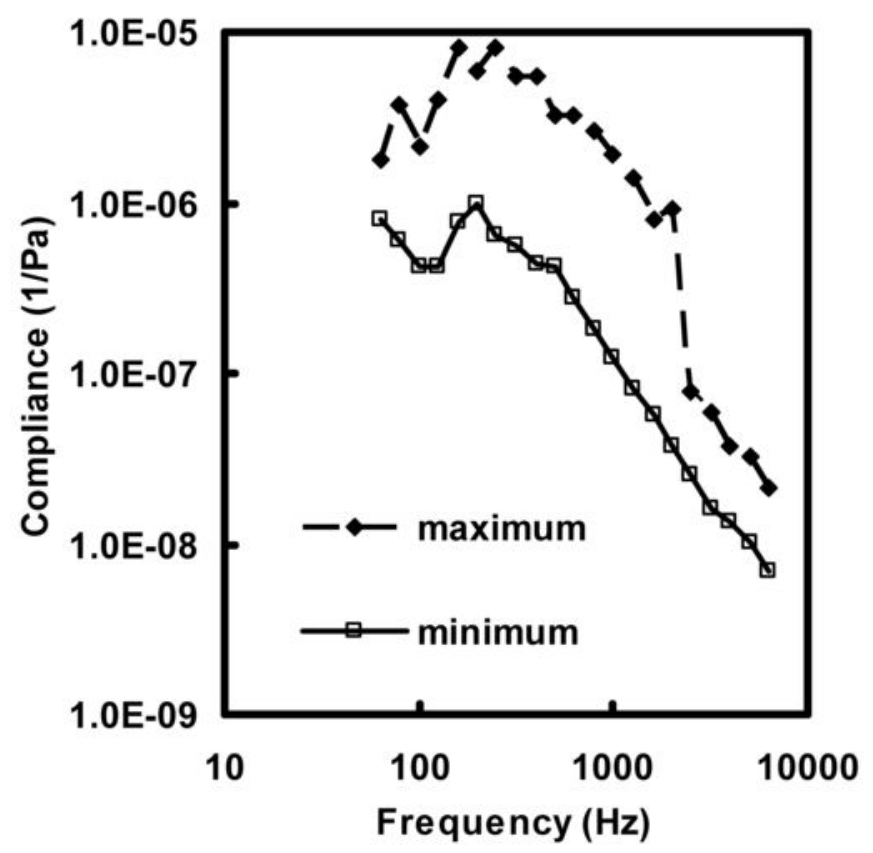




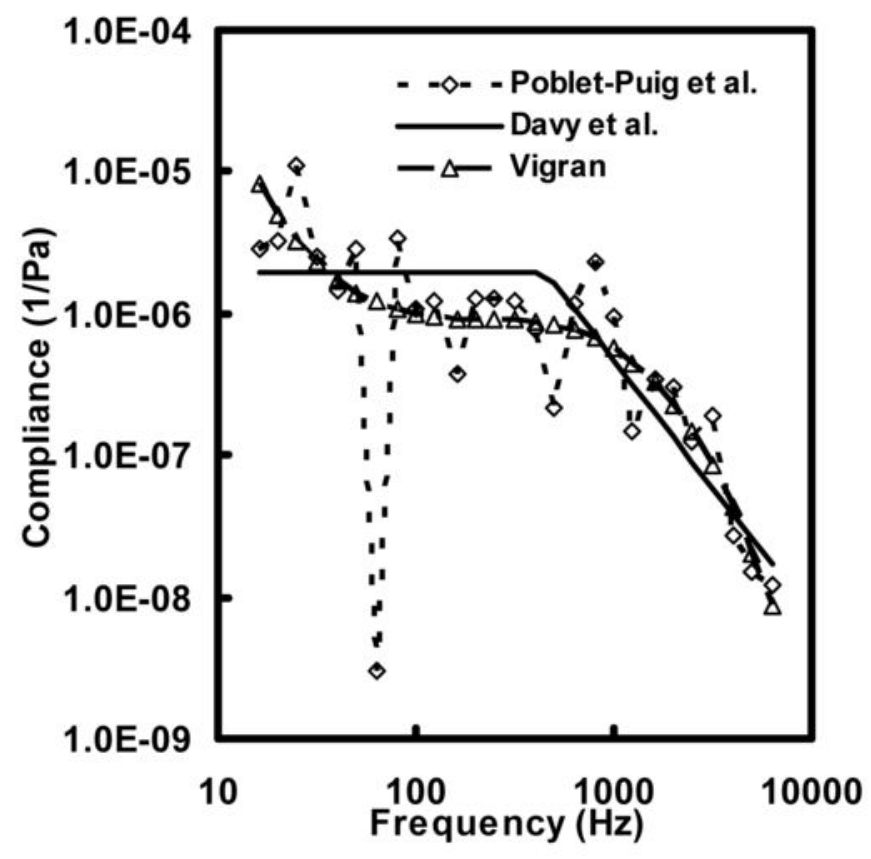




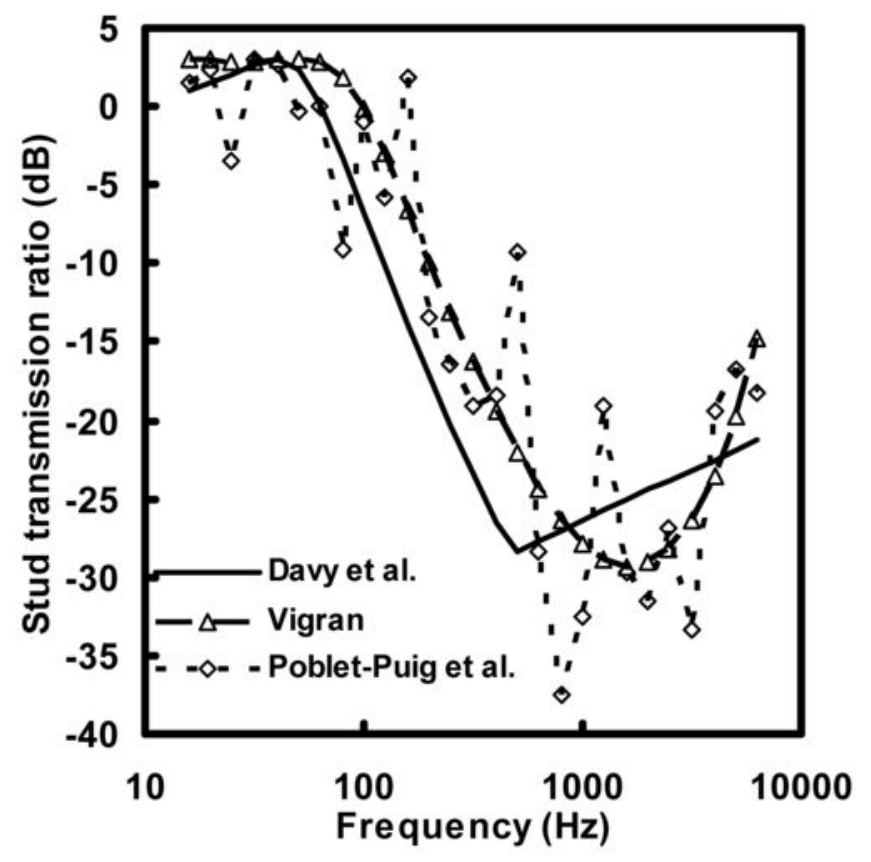




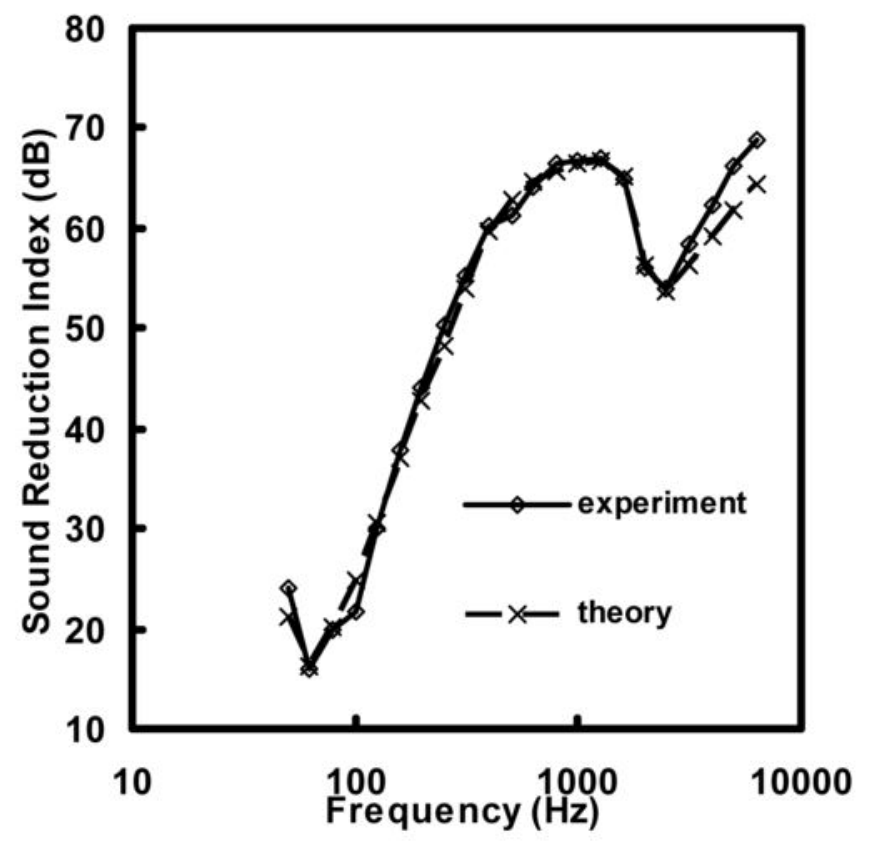




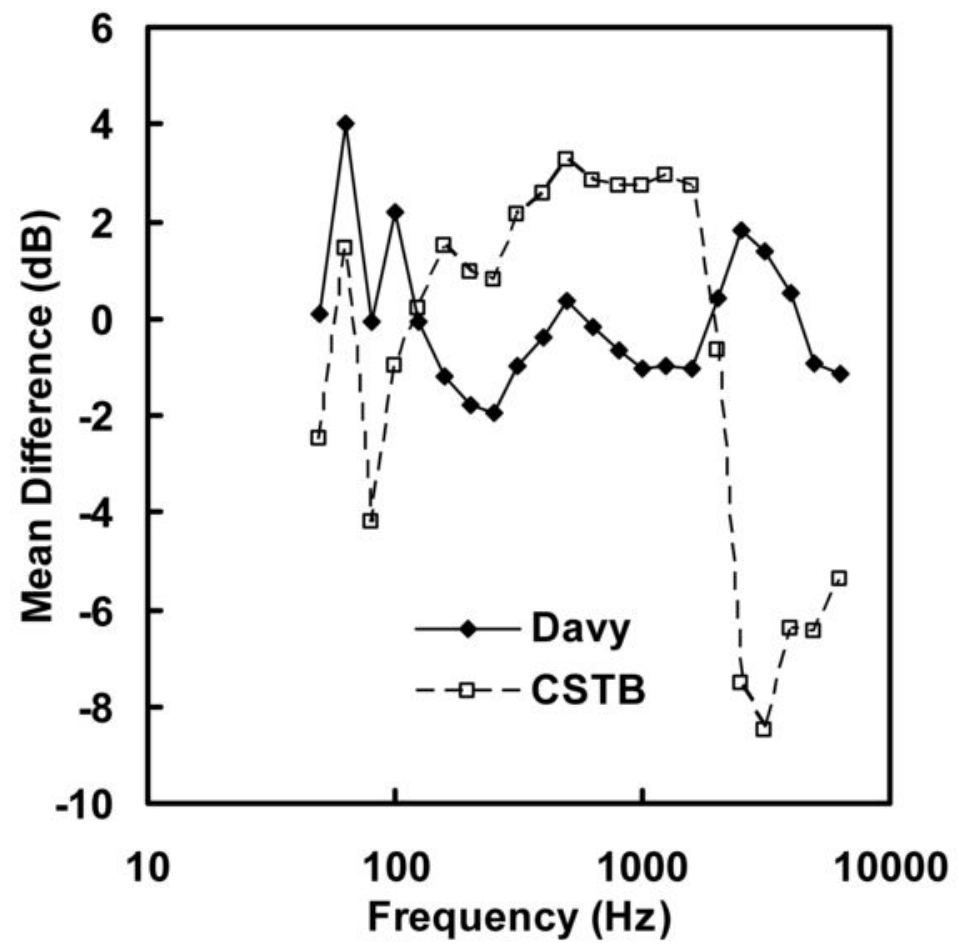




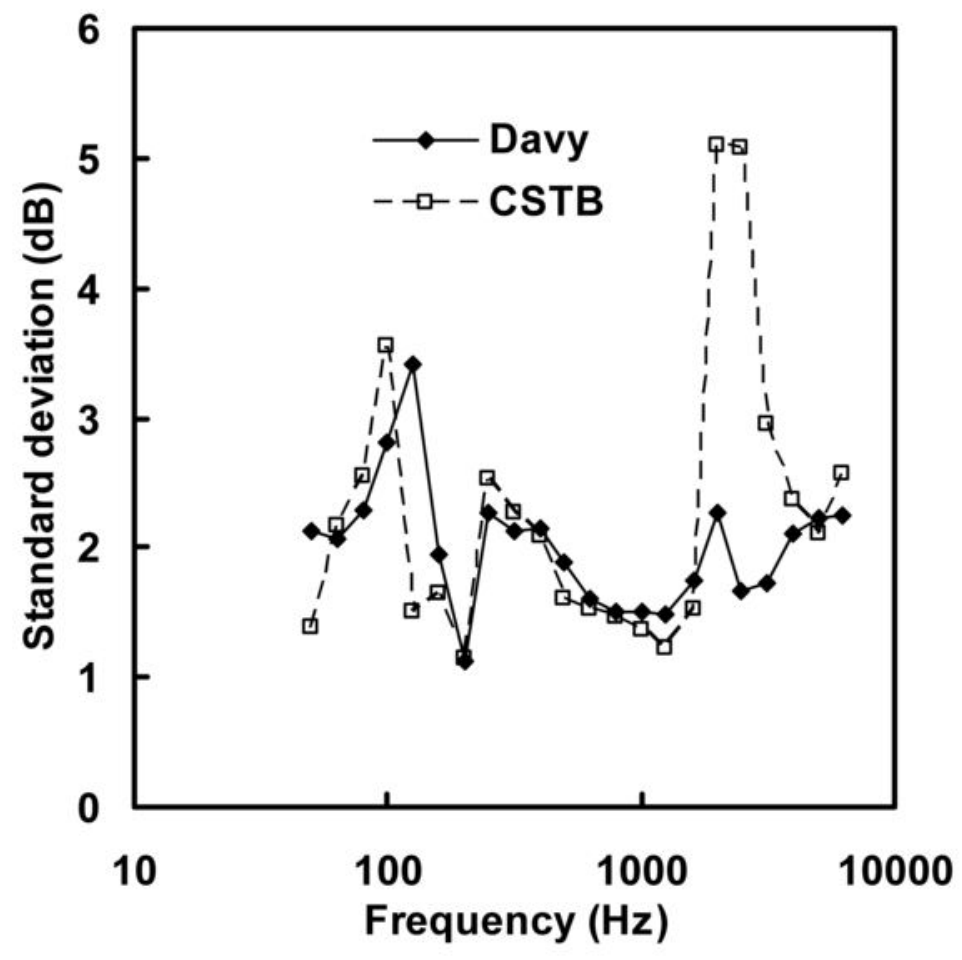




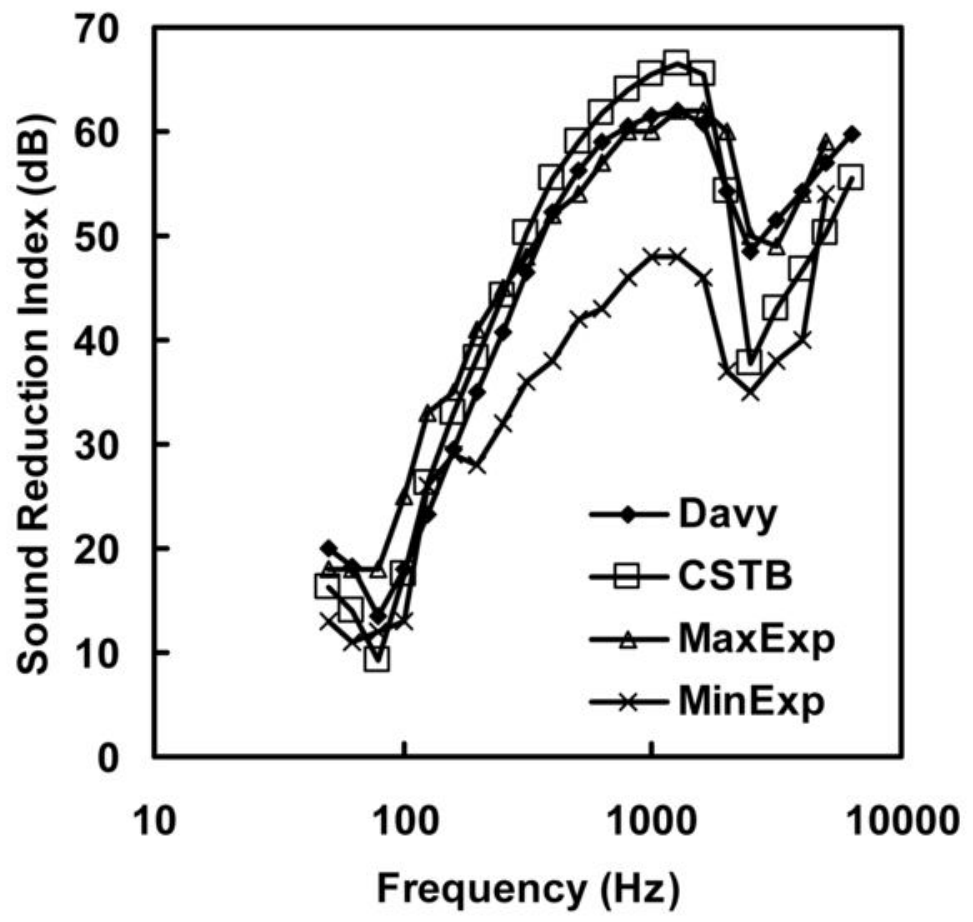




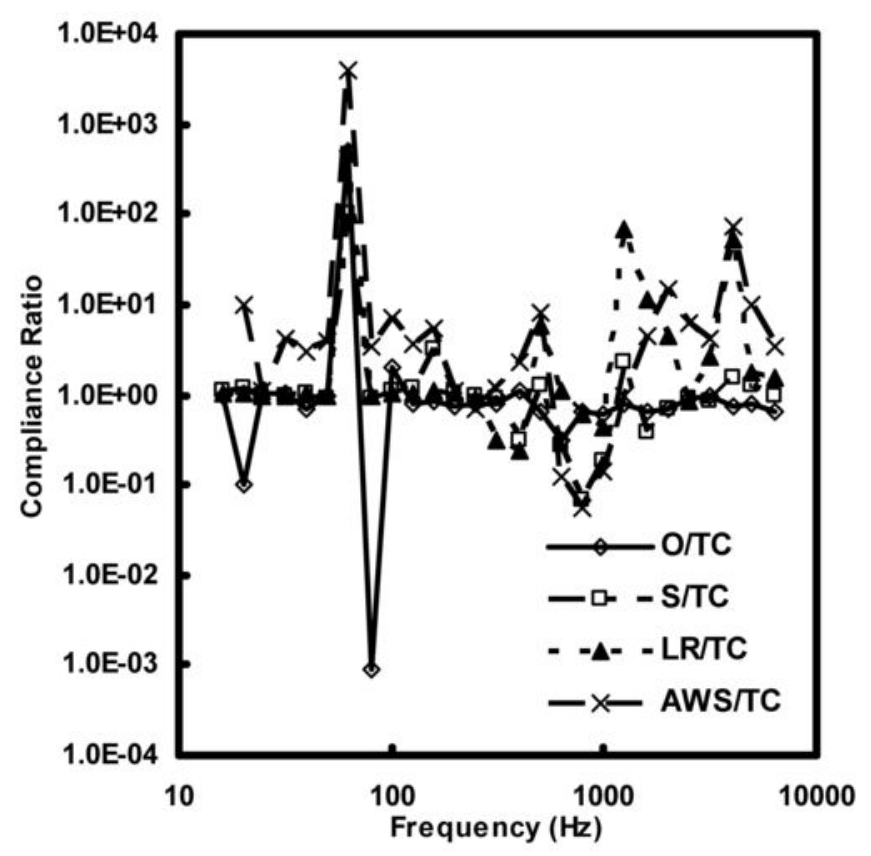

